\title{
Early spatial language development and education: a scoping review
}

\author{
Dandan $\mathrm{Wu}^{1} \cdot$ Hui $\mathrm{Li}^{1} \mathrm{D} \cdot$ Sheila Degotardi ${ }^{1}$
}

Received: 8 May 2021 / Accepted: 13 September 2021 / Published online: 13 October 2021

(C) The Author(s) 2021

\begin{abstract}
Early spatial language plays an important role in facilitating cognition and thoughts thus deserves empirical studies. This scoping review aims to synthesis the empirical evidence to identify the key topics, major findings, and research gaps regarding early spatial language development and education. The search has identified 19 studies published in the international peer-reviewed journals during 2000-2021, converging into three common topics: the developmental patterns of early spatial language, its role in child development, and parental influences. First, the synthesis of evidence revealed a significant age effect but an inconclusive gender effect in early spatial language. Second, the modeling or regression results jointly indicated that early spatial language could facilitate or predict spatial skills and/or spatial cognition. Third, the existing evidence supported that parental language input and parental involvement could enhance early spatial language. However, this study also found the major research gaps: no Chinese studies, very few naturalistic studies, the understudied 'motion events', and no studies on 'frames of reference'. Implications for future studies and practical improvements are also discussed.
\end{abstract}

Keywords Spatial language $\cdot$ Early years $\cdot$ Child development $\cdot$ Early spatial language

\section{Introduction}

Early language has laid a solid foundation for early cognitive development, especially those about space and spatial relationships (Bower et al. 2020). For example, an increasing volume of research shows that spatial cognition is affected by early spatial language (Bohnemeyer 2020), providing evidence to support the Whorf hypothesis that language features would shape its speakers' world view or cognition as it provides symbol systems to represent the world (Hussein 2012). This

Hui Li

philip.li@mq.edu.au

1 School of Education, Macquarie University, Sydney, Australia 
hypothesis has inspired decades of exploring the complicated and dynamic relationships between language and thoughts concerning early spatial cognition (Bower et al. 2020). Thus, it is critical to conduct a synthesis or scoping review to understand what has been explored and reported about the topic. This scoping review aims to examine a wide breadth of research resources during 2000-2021 related to the exploratory questions regarding early spatial language development and education to meet this need.

\section{Spatial language and its semantic categories}

Spatial language is the language of spatial concepts and relationships, usually consisting of words and phrases used to describe the spatial relationship between objects and attributes (Bower et al. 2020). Different languages have their linguistic systems to encode spatial information to express spatial concepts and spatial relationships (Bower et al. 2020; Bowerman and Choi 2003). Bowerman (1996) proposed the 'spatial semantic categories' that could be used in human cognition to distinguish the motion or location of objects in space, thereby meeting the need for communications. For example, the containment category uses a localizer (or preposition) 'in' in English. Gentner and Bowerman (2009) suggested that investigating spatial semantic categories to generate typological frequency could provide significant clues to understand the nature of language and language acquisition. They further concluded that spatial semantic categories might not be equipotent in the learning process, which means that some spatial semantic categories could be harder to learn (Gentner and Bowerman 2009). For the first time, Gentner and Bowerman (2009) emphasized the learning process by examining the typological frequency of spatial semantic categories to replace the 'concepts first or language first?' question with the question of 'which semantic categories of space does a child most readily learn with the help of her language?'. In this sense, examining the full typology of spatial semantic categories in the early years is urgently needed.

The classification of spatial semantic categories varies for different research purposes. First, to meet the need for crosslinguistic comparisons, Levinson and Wilkins (2006) proposed a 2-category coding system of spatial language (see Fig. 1, conceptual domains of spatial information): Static Spatial Information ('stasis'), and Dynamic Spatial Information ('kinesis'). In particular, most researchers agreed that

Fig. 1 Conceptual domains of spatial information by Levinson and Wilkins (2006). "The partition itself reflects major conceptual cleavages in the domain: stasis versus kinesis on the one hand, and angular versus non-angular static descriptions on the other." (Levinson and Wilkins 2006, p. 3); Stasis $=$ Static $;$ Kinesis $=$ Dynamic

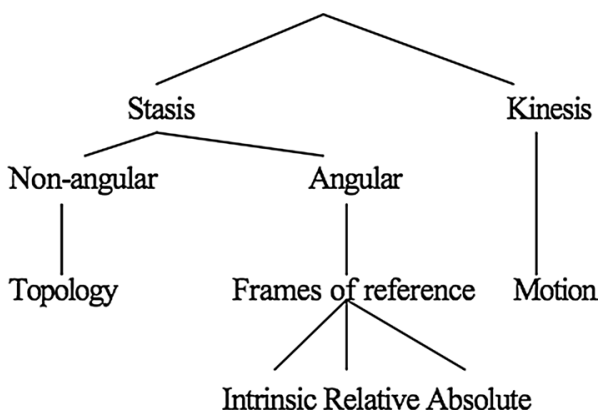

Intrinsic Relative Absolute 
human language encodes static spatial information in several basic categories: (1) Location to indicate where the objects or people are, (2) Spatial Relations between these objects or people; and (3) Motion events to encode the dynamic spatial information and the moving path (Clements et al. 2003; Ji et al. 2011; Bowerman and Choi 2003). In addition, Levinson and Wilkins (2006) have also provided another perspective to observe human's spatial descriptions - the angular or non-angular partition (Fig. 1), which emphasized the Frames of Reference (FoRs) employed in human's spatial language. And the three common perspectives of FoRs include the Intrinsic, Relative, and Absolute ones (Levinson and Wilkins 2006).

Second, to examine the spatial language of both children and caregivers in the field of early development and education, Cannon et al. (2007) established a system to code English spatial language into eight categories: (1) spatial dimensions (i.e., size-big, small); (2) shapes (i.e., square); (3) locations and directions (to describe relative positions); (4) orientations and transformations (i.e., turn right); (5) continuous amount (i.e., whole, piece, portion, etc.); (6) deictics (i.e., here, there, where, etc.); (7) spatial features and properties (i.e., side, curve, round, line, etc.); (8) pattern (i.e., next, after, sequence, increase, decrease). In fact, among these eight categories, only the (4) 'orientations and transformations' belongs to the motion category in space (dynamic spatial information). Besides, this eight-category scheme mainly targets the lexical level of spatial language (spatial terms), which is not suitable for processing spatial information coding at the sentence level. In this sense, the first scheme proposed by Levinson and Wilkins (2006) can cover the largest variety of spatial information at both lexical and sentence levels. However, it is unknown whether all these categories could be observed in early spatial language and whether this system applies to the Chinese language. Therefore, there is a need to systematically review the existing studies on spatial language acquisition, focusing on the applicability of these categories in early child Chinese.

\section{Early spatial language development}

Language development is a long-term journey, possibly starting from the fetal period when the mother's speech could be heard (Pang and Li 1993). Most infants can produce their first word by the end of the first year and learn words to mark their world. However, words describing spatial relationships such as size and location are difficult for young children to learn, as the young minds might not understand those abstract concepts (Piaget 1926, 1928). Thus, early spatial language plays an important role in acquiring spatial cognition and skills, as the existing evidence indicates that parental language input can enhance young children's performance on spatial comprehension tasks (Szechter and Liben 2004). Furthermore, their spatial language can also predict later spatial performance (Polinsky et al. 2017). Therefore, early spatial language, including comprehension and production, is highly associated with spatial cognition development.

Early spatial language develops in the first year, when infants begin to develop basic representations and categories for spatial terms from 3 to 10 months old (Casasola et al. 2003; Quinn et al. 2003). They usually begin to produce and understand 
simple spatial prepositions around 2 years old (Meints et al. 2002; Weist et al., 2000) and more complex prepositions around 5 years old (Foster \& Hund, 2012; Weist et al., 2000). Balcomb et al. (2011) found that spatial language production during 16-24 months of age was significantly correlated with their later performance in later spatial tasks. Pruden et al. (2011) found that parental spatial language input during the first three years was highly correlated with children's performance in many spatial tasks at age 4.5. Some other studies have shown that children with more exposure to spatial language perform better on spatial tasks (Miller et al., 2016). These findings jointly indicated that early spatial language could facilitate the later development of spatial skills and performance. However, no synthesis or scoping reviews have systematically reviewed these findings to see whether they are universal, crosslinguistic, and cross-contextual. In particular, there is a critical need for a better understanding of early spatial language development in Chinese preschoolers that could be employed to develop early childhood education and teacher education programs.

Early spatial language is difficult to learn and use, especially for young children. This is because that the position of the object in space can be described in many ways. For example, the object can be under the cup and on the table simultaneously, which increases the complexity of parsing the meaning of these words in daily speech. In addition, whether an object is behind or in front of another object depends on the speaker's position relative to the object. Since the speaker's position is not always the same as the child's, this requires the child to engage in perspective-taking, a later-developed skill. In addition, early spatial language production and skills are also closely related to environmental factors and spatial experience (Levine et al. 2012). For example, compared with parents with high SES, parents with low SES reported that their children used significantly fewer space words (Verdine et al. 2014). Therefore, understanding how parental input and family influences could facilitate early spatial language development, especially in Chinese preschoolers, and the findings will help develop effective parent education programs in China.

\section{The role of early spatial language}

Spatial cognition is a mechanism for representing and reasoning about specific spatial relationships of ecologically significant entities and events (Spelke 2000). It depends on the cognitive tools or frameworks provided by languages. Therefore, researchers have noticed a close relationship between spatial language and children's spatial cognition (Ferrara et al. 2011; Landau and Jackendoff 1993; Munnich et al. 2001; Wallentin et al. 2005). Pruden et al. (2011) found that children's spatial items from 14 to 46 months can predict their performance in nonverbal spatial tasks at 54 months. There is also evidence that acquiring specific spatial words may affect children's spatial skills. For example, preschoolers who have learned left/right words can use landmarks to find hidden objects than children who have not learned words (Hermer-Vasquez et al. 2001). Before determining the relevant terms in the early stages of development, reminding children to pay attention to specific spatial terms can improve their spatial performance. However, these findings are consistent with 
expectations that spatial cognition benefits from spatial language; they are open to other interpretations in many cases. For example, the benefits of using spatial language at task time may be interpreted as temporary priming effects; the correlation between children's control of spatial language and their non-verbal spatial abilities may only reflect some of the third factors' effects, such as the maturity or experience advantage. Accordingly, another critical need is to systematically review the existing studies on the dynamic and complicated relationships between early spatial language and early spatial cognition across languages and contexts.

Another long-term interest in language studies is the relationship between language and thought. Sapir and Whorf proposed the so-called Sapir-Whorf hypothesis. This hypothesis has two main aspects: first, the structural differences between languages are parallel to the cognitive differences of language users; second, a person's mother tongue affects their way of thinking (Bohnemeyer 2020). The SapirWhorf hypothesis has inspired decades of psychological and linguistic research, trying to understand how a person's spoken language affects cognition and the extent to which cognition affects language development (Bowerman and Choi 2003). However, this hypothesis has been challenged because early spatial language might be reversely affected by early spatial thoughts. For instance, Wu et al. (2018) found that Chinese-speaking preschoolers could produce only four of the six types of the pragmatic meaning of 'shang (上)', a spatial term widely used to denote the position of objects. This is because the young children could only understand the four types of physical space: supporting, attaching, positioning, and containing. Their thoughts were not mature enough to understand the two types of psychological space; thus, they could not express them in their language production. Wu et al. (2018) study has shed light on exploring the complicated relationships between cultural context, cognitive and thought development, and language acquisition. However, no synthesis or scoping reviews have been conducted to summarize the latest evidence about these relationships. Besides, given that spatial language influences spatial cognition development, it is important to understand how to enhance spatial language development via educational support from both school and family sides. Therefore, we conducted a scoping review of the existing literature about early spatial language development and education to fill this gap.

\section{Methods}

This study applied a scoping review methodology, which has been widely used to examine the depth of research on a given topic, to summarize research findings for policymakers, practitioners, or consumers, identify research gaps, and establish the areas for future research (Arksey and O'Malley 2005; Levac et al. 2010). This method matches this study that aims to explore the width and depth of exiting studies on early spatial language, identify research gaps, and establish the areas for future research. In particular, this study has searched, identified, collected, examined the potential sources for their relevance to the research objectives, and mapped them to the key themes and concepts underpinning the research questions. Five phases were followed in conducting the current scoping review: (1) articulating the research 
questions; (2) identifying relevant studies; (3) selecting studies; (4) charting the data; and (5) collating, summarizing, and reporting the results.

\section{Phase 1: articulating the research questions}

We proposed the following questions to guide this study: (1) How does spatial language develop in the early years? (2) What are the roles of early spatial language in children's development? (3) What are the influential factors of spatial language in the early years? (4) What are the research gaps in this field of studies?

\section{Phase 2: identifying relevant studies}

An extensive automated search of electronic resources in three databases (i.e., ProQuest, Scopus, and Google Scholar) took place in February 2021. The literature search aimed to thoroughly identify all the research articles on "early spatial language development and education" published during 2000-2021. Four different sets of terms with two Boolean operators (AND and OR) were utilized to search for and extract relevant literature from the databases: (early) AND (spatial language OR expression OR cognition OR thoughts OR development OR acquisition) AND (early childhood OR early child OR preschool OR pre-K OR prekindergarten OR pre-kindergarten OR kindergarten OR young children OR pre-schoolers OR preschoolers OR kindergarteners OR ages 3-8 OR 3-8 years) AND (education OR teaching OR learning OR developing OR facilitat*). We created the search terms through extensive piloting.

\section{Phase 3: selecting studies}

We followed a set of criteria to ensure that only full-text, peer-reviewed journal articles meeting the objectives of this systematic review were included. Inclusion criteria were as follows:

(1) Published journal articles reported on early spatial language development and education;

(2) Early spatial language in normal children was examined;

(3) Results reported on early childhood spatial development and education covering young children aged $0-8$ years.

(4) Empirical research used either corpus (natural) or experimental designs;

(5) The sample size of the study should be more than 10; and

(6) English was the written language.

We excluded case studies, children with special needs studies, literature reviews, and commentary studies without empirical data.

Figure 2 shows the screening and selection process. After reading the abstract or skimming the full texts of references (in cases where the abstract information did not adequately address the inclusion and exclusion criteria), a list of 22 studies meeting 


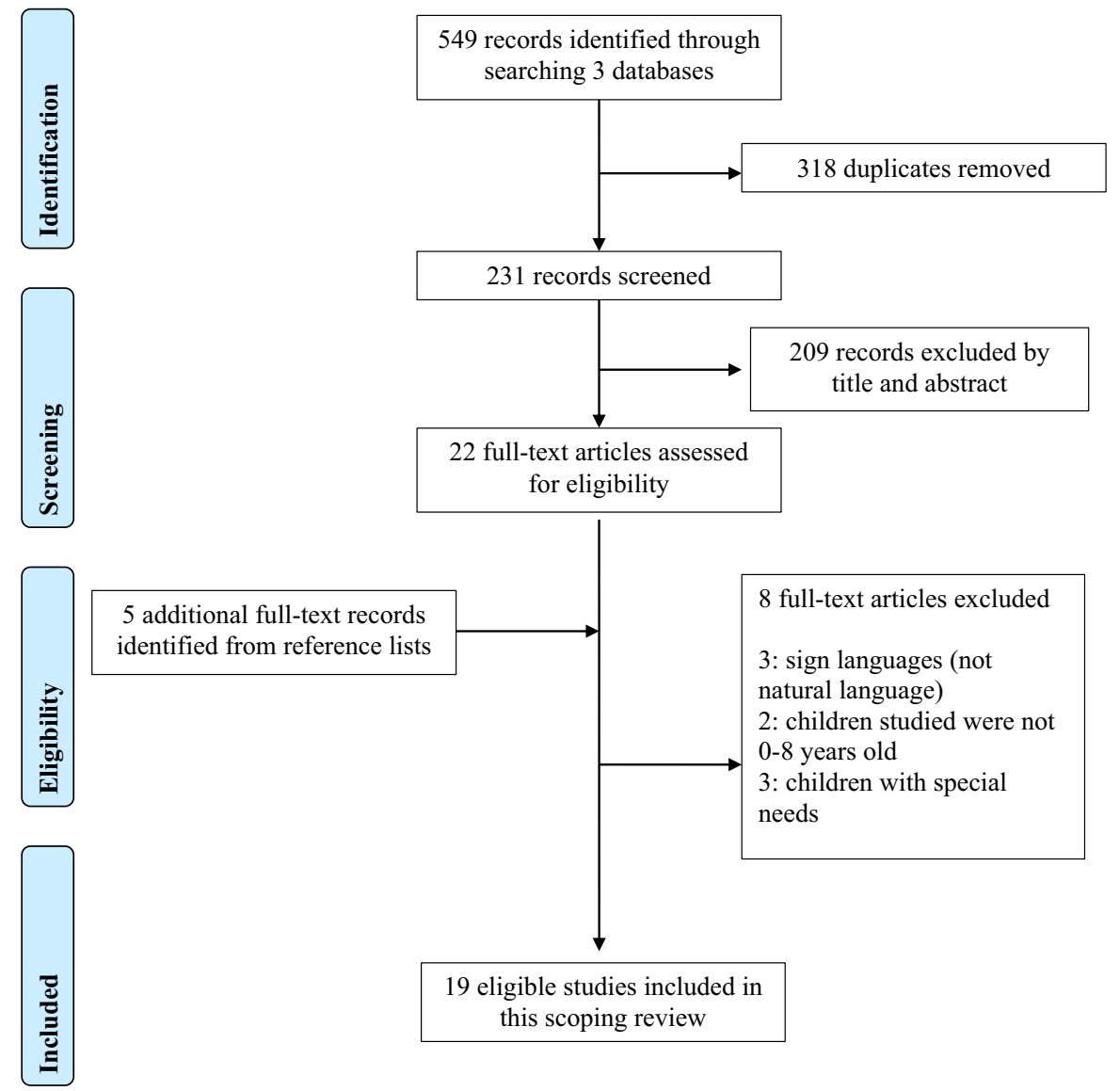

Fig. 2 The selection of studies included in this systematic review

the inclusion criteria was created. The reference lists of the potentially eligible studies were also read to identify any studies not found in the databases. Then, any newly identified studies were included. Next, the first and second authors independently reviewed and selected the articles based on the inclusion criteria, and the agreement was $89.5 \%$. Then they discussed the studies that were uncertain to be eligible or not until reaching $100 \%$ agreements. Finally, 19 studies met all the criteria and were included in the final analysis.

\section{Phase 4: charting the data}

The 19 included sources were charted to examine the types of research identified (see Table 1). The majority of sources were experimental studies $(n=13)$, and the rest were six natural conversation observations. In terms of the age range of the sample, six sources included very young children aged 0-3 (infant and toddler age), 


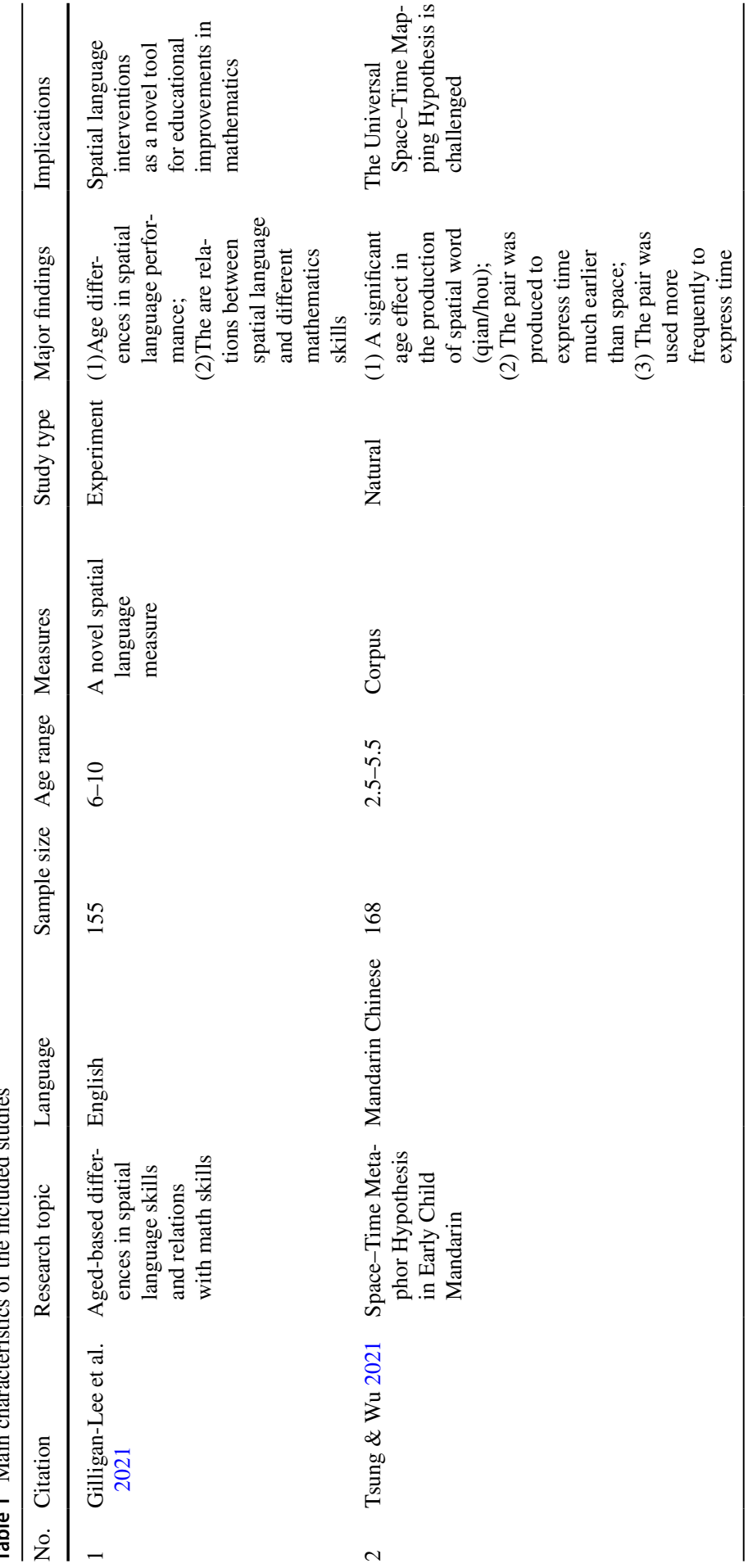

SN Social Sciences

A SPRINGER NATURE journal 


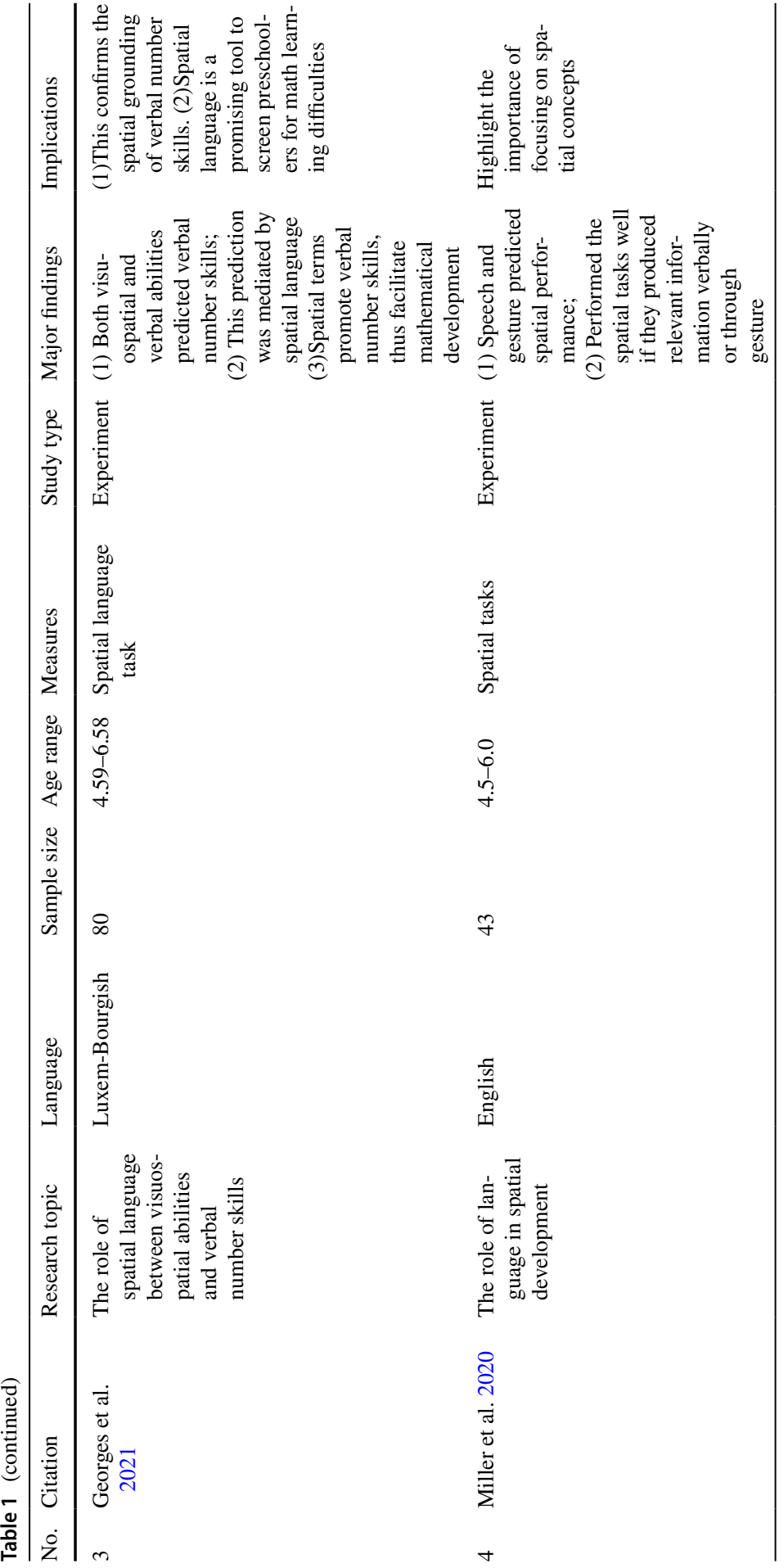




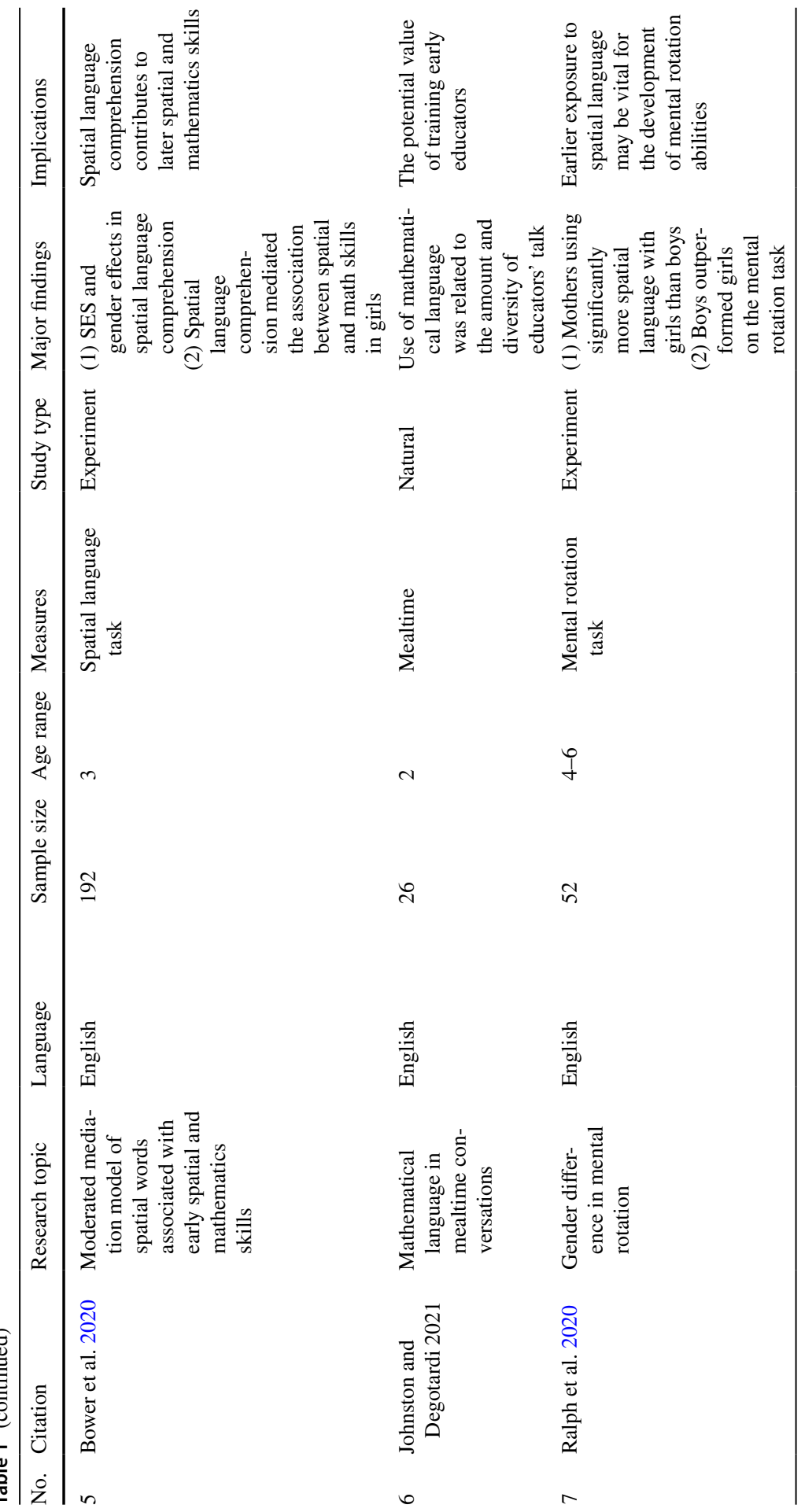

SN Social Sciences

A SPRINGER NATURE journal 

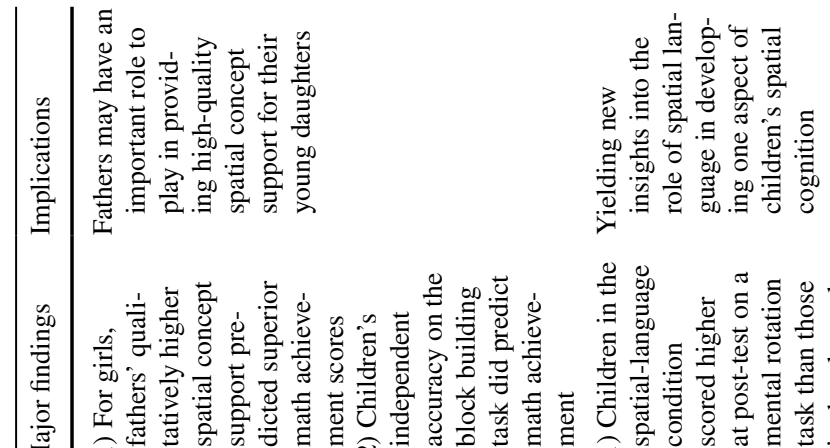

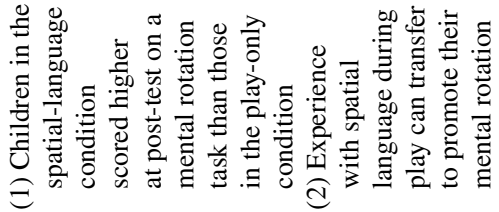

苛

童

$\checkmark$

in

5
$\frac{5}{60}$
जี

㐫.

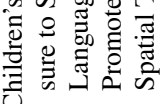

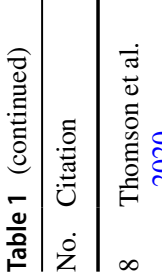

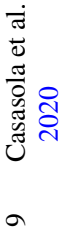




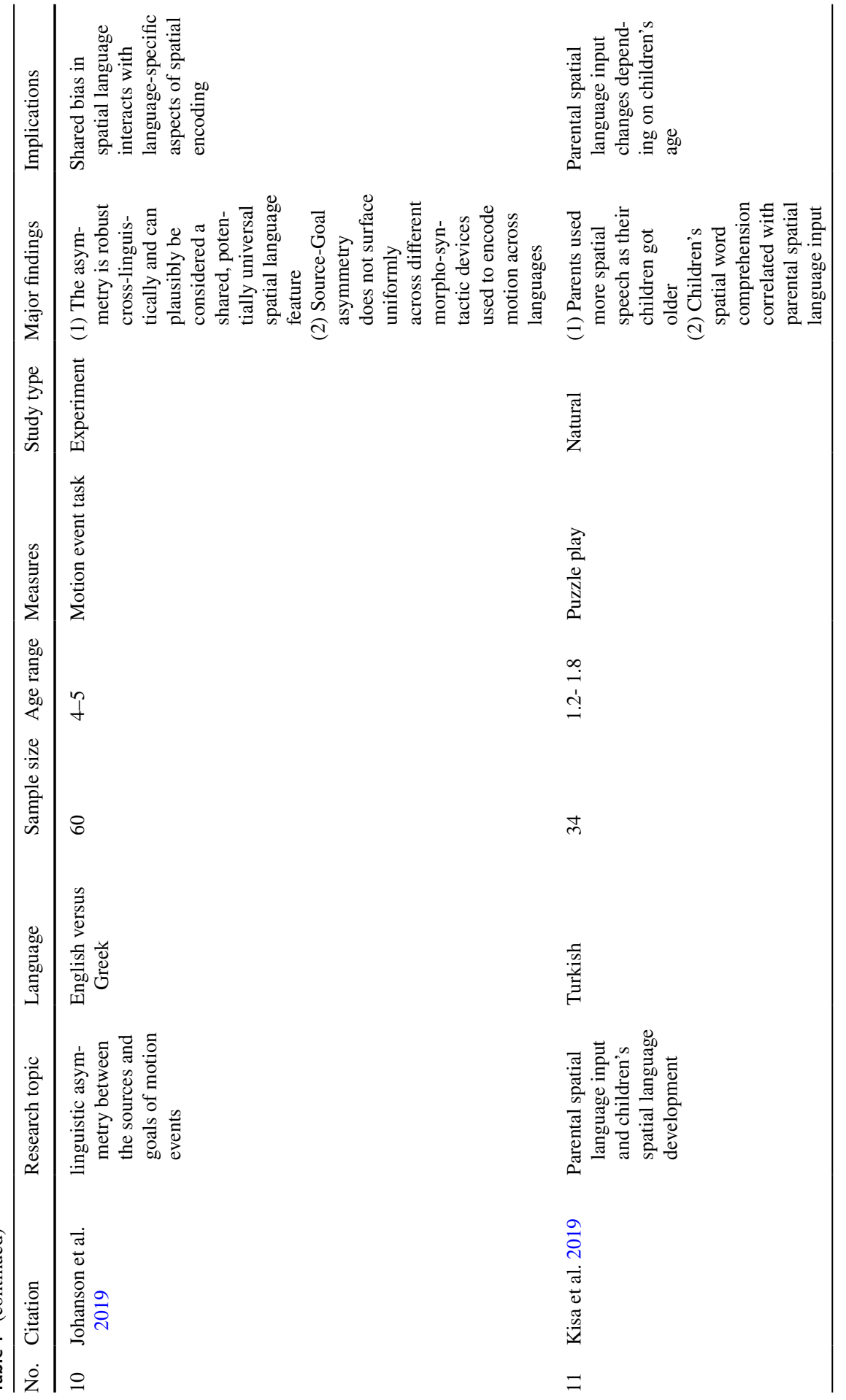

SN Social Sciences

a SPRINGER Nature journal 


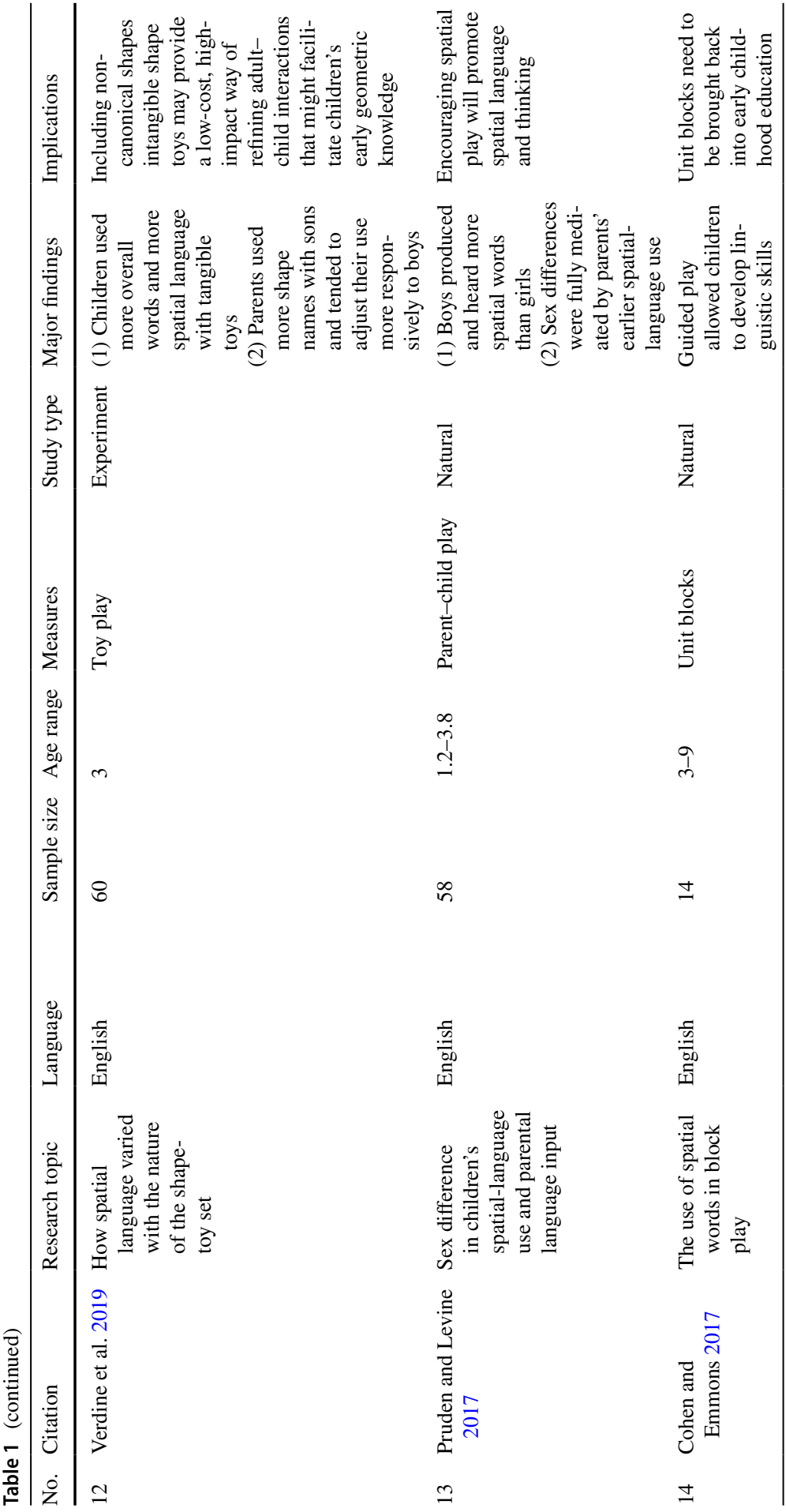

SN Social Sciences 


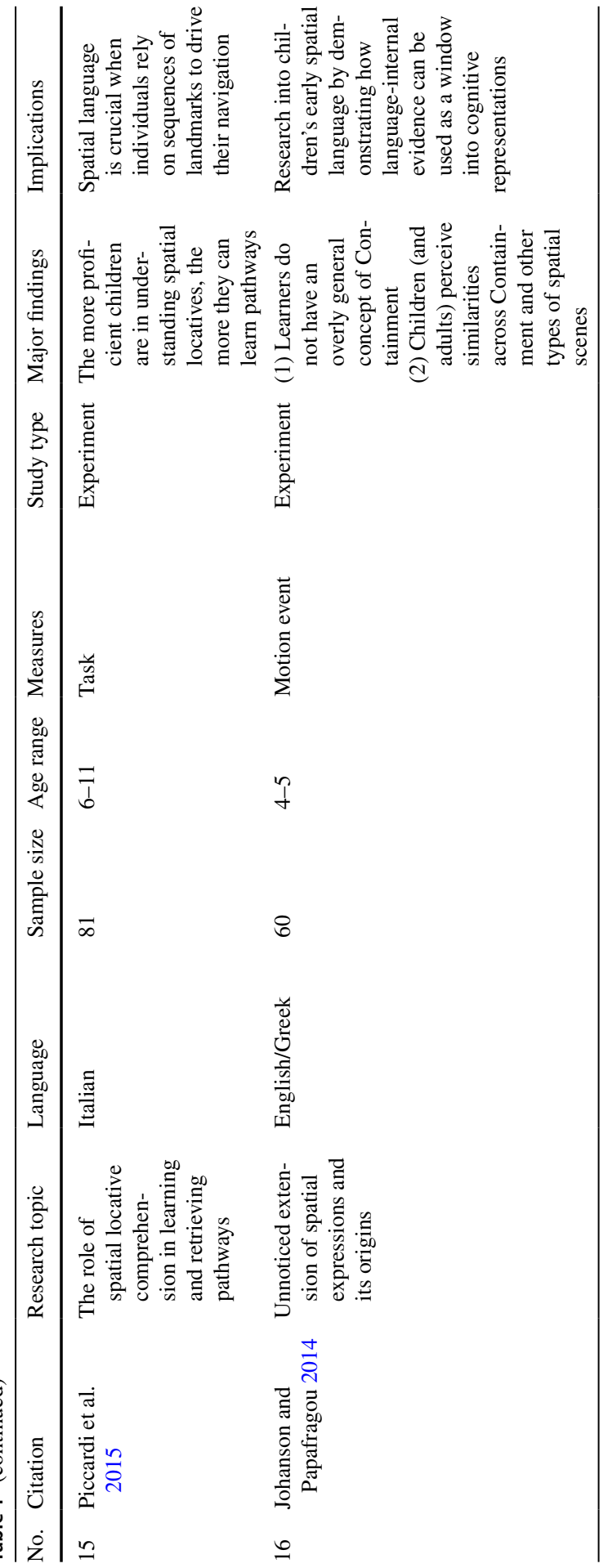

SN Social Sciences

A SPRINGER NATURE journal 


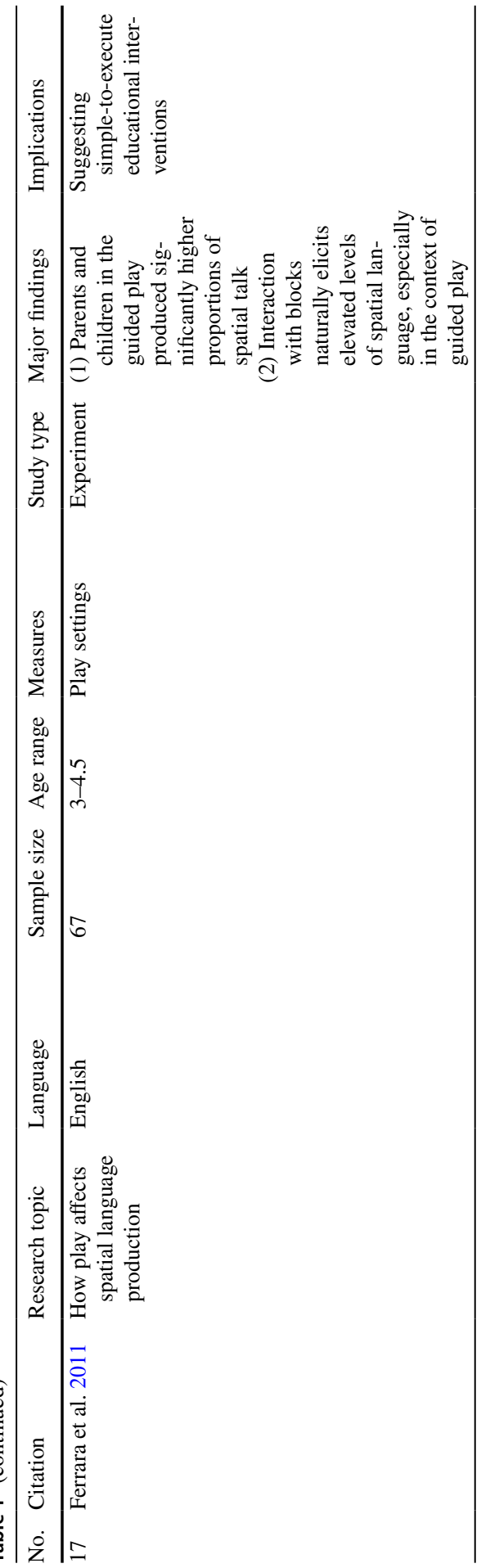




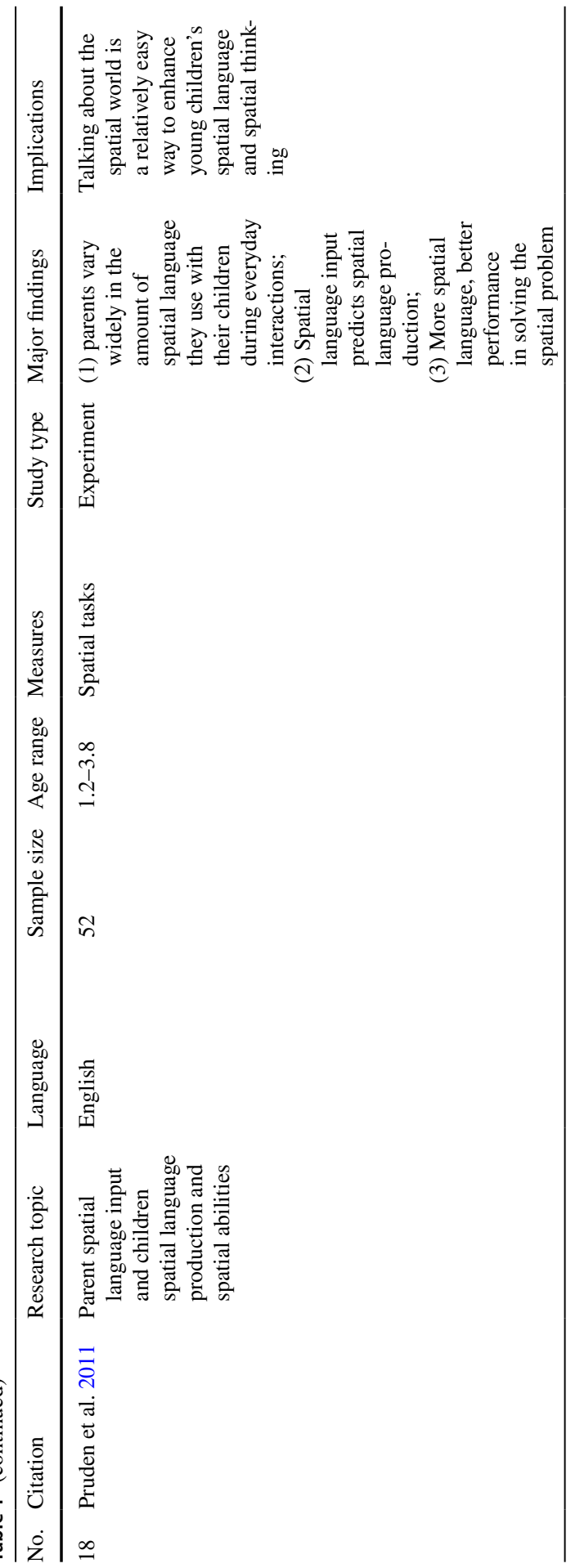

SN Social Sciences

A SPRINGER NATURE journal 


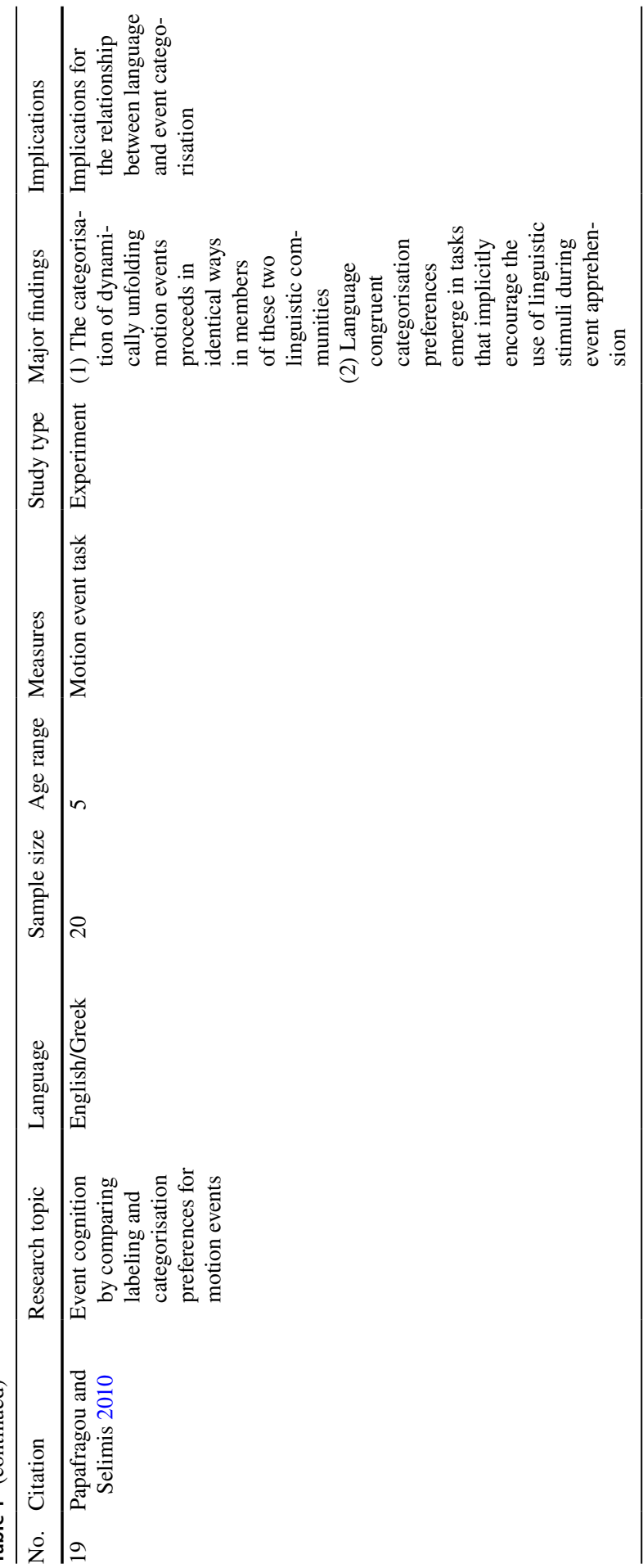


12 sources included kindergarten children aged 3-6 (preschool age), three sources included participants aged 6-12 (primary school age). Regarding the language being studied, 15 sources were about English, three were about Greek, followed by few studies on other languages (Luxembourgish, Turkish, Italian), and only one source studied Mandarin Chinese.

\section{Phase 5: collating, summarizing, and reporting results}

We extracted and collated the following essential information: authors, year of publication, research procedure, sample size, age of participating children, language, research design, and research findings. The first author independently reviewed the included articles and extracted data using a pre-established coding scheme. This coding scheme is used to collate and summarize the sources in five aspects, including (1) target semantic categories of spatial language, (2) developmental pattern of spatial language, (3) the role of spatial language in early development, (4) the influential factors of spatial language development, and (5) the methodological matters. Any inconsistency was resolved through discussion and consensus with the co-author(s).

\section{Target semantic categories of spatial language}

The first step in organizing results was to collate the target semantic categories of spatial language being studied. Collating the target semantic categories of spatial language was an important step in gaining a sense of spatial categories available on the issue of interest. According to the semantic category framework proposed by Levinson and Wilkins (2006), the spatial semantic categories were firstly classified as two aspects (Bowerman 1996; Levinson and Wilkins 2006): static information category (i.e., location, relation, deixis) $(n=17)$, and dynamic information category (i.e., orientation, transformation, or motion events) $(n=2)$. And secondly, we also coded the target semantic categories of spatial language in angular (Topology) $(n=19)$ or non-angular (Frames of Reference) $(n=0)$ ways.

\section{Developmental pattern of spatial language}

The developmental pattern was also coded, focusing on the trends and features of the language-learning process, showing milestones in different developmental stages such as babyhood, toddlerhood, and childhood (Piaget and Inhelder 1956). The developmental trend in language acquisition is generally reflected by the starting point or emerging time point of certain vocabularies or sentences in the early years (Lightfoot 2010; Chomsky 1959). Given that spatial cognition was commonly found to have gender differences from childhood throughout adulthood (Lawton 1994; Tzuriel and Egozi 2010; Levine et al. 2005), it is also vital to observe if there is any gender difference in spatial language development. Therefore, this scoping review 
collated the developmental pattern of spatial language among the literature into age differences $(n=2)$ and gender differences $(n=3)$.

\section{The role of spatial language in early development}

The role of spatial language in early development was also coded, as spatial language has been confirmed as a key variable influencing the spatial cognition and other related domains of early development (Ferrara et al. 2011; Landau and Jackendoff 1993; Munnich et al. 2001; Wallentin et al. 2005). To collate the contributions of spatial language in early development, we coded the existing sources into two types: the facilitating role $(n=3)$ versus the mediating role $(n=3)$. The facilitating role means that the spatial language contributes to the outcome variable(s). In contrast, the mediating role means that the spatial language functions as a mediator among the certain relationship between the other two variables.

\section{The influential factors of spatial language development}

Next, the influential factor of spatial language development was coded. Previous studies have explored the influences mainly from family on language development (Dessalegn and Landau 2013; Gentner et al. 2013; Pruden et al. 2011; Shusterman, Ah Lee, \& Spelke 2011; Verdine, Lucca, Golinkoff, Hirsh-Pasek, and Newcombe 2016). Therefore, the influential factors, including the facilitator $(n=3)$ and the mediator $(n=1)$ of spatial language development, were also collated in the present study.

\section{The methodological matters}

The methodological issues of the 19 sources were collated and reviewed to overview the existing research design and the potential gaps resulting from the methodology. As the vital step of literature review, analyzing the methodological matters in the existing sources provided a comprehensive framework to rethink the research design and potential gaps of investigating spatial language development. Two aspects of methodological matters were concerned and classified as follows: the languages being studied $($ English $=15$, Greek $=3$, Luxembourgish $=1$, Turkish $=1$, Italian $=1$, Chinese $=1)$, and the research approaches (Experimental $=13$, Naturalistic $=6$ ).

\section{Results}

Nineteen studies were identified and reviewed in this study. The main characteristics of and the magnitude of effects across the included studies can be found in Table 1. The synthesis of evidence revealed various topics and methods on early childhood spatial language development and education. This section will address the four research questions that have driven this systematic review: the age and gender differences in early spatial language, the role of early spatial language, parental influences on early spatial language, and the research gaps. 


\section{Age and gender differences in early spatial language}

The first and fundamental question about early spatial language is whether there are significant age and gender differences in the early years. Unfortunately, very few studies have explored this question for the languages of English and Chinese.

\section{Age differences}

Among the 19 studies under review, only two studied the age differences in early spatial language. First, Gilligan-Lee et al. (2021) conducted a cross-sectional study to explore age differences in English spatial language performance from 6 to 10 years. The mixed ANOVA analysis found a main effect of age group, and effect size ranged between 0.23 and 0.33 (Gilligan-Lee et al. 2021). For spatial language comprehension, post-hoc tests revealed significantly lower performance at age 6 than age 8, 9, and 10 years, and age 7 compared to 9 and 10 years. There was also a significantly lower performance for spatial language production at ages 6,7 , and 8 years than at ages 9 and 10. Their study confirmed the significant age differences in spatial language production and comprehension tasks. Second, Tsung and Wu (2021) examined the age difference in the production of a pair of Chinese spatial words qian (before/front) and hou (after/back) in a toy play context. Using a corpusbased approach to investigate Chinese preschoolers (ages 2-6), they found a significant age effect in the production of "qian/hou, the pair was produced to express time (before/after) much earlier and more than space (front/back). The two studies indicated that there might be significant age differences in early spatial language, including comprehension and production. Further studies, however, are needed to confirm this developmental pattern.

\section{Gender differences}

Among the 19 studies under review, only three explored the gender difference. First, Pruden and Levine (2017) confirmed that parents' earlier spatial-language input fully mediated the gender differences in spatial language talk, thus encouraged spatial play to promote spatial language and thinking. Second, Bower et al. (2020) have explored the potential moderating effects of gender, socioeconomic status (SES) on the possible mediation of spatial language on the relationship between spatial skill and mathematics performance. Altogether 192 age 3 English speakers were tested with Spatial Language Comprehension Task, Test of Spatial Assembly, and mathematical assessments. The results indicated a gender difference in spatial language comprehension, with girls having higher spatial language comprehension than boys. Third, Ralph et al. (2020) found that boys outperform girls in psychological rotation development by age 5, and parental language input is one reason. In particular, the mothers used more spatial language with boys than girls in PreK years, whereas more for girls in the post-K years. The three studies jointly indicated that there might be significant but conflicting gender differences in early spatial language, which might be a consequence of the interactions between nature and nurture factors. Further studies, however, are needed to explore and confirm this gender effect. 


\section{The roles of early spatial language}

This review found that early spatial language might play two important roles: facilitator of early spatial development and mediator of the relationship between other factors and early spatial and mathematic skills.

\section{The facilitating role}

Piccardi et al. (2015) found that spatial language played an important role in early spatial cognition and operation in learning and retrieving pathways in 6- to 11-yearold Italian children. Miller et al. (2020) found that spatial language predicted spatial performance after controlling for age, gender, and gestures and suggested developing the early spatial concept to facilitate early spatial development. Finally, Casasola et al. (2020) experimented and found that spatial-language training significantly enhanced young children's mental rotation.

\section{The mediating role}

Pruden et al. (2011) explored the complicated relations between parent spatial language input, children's spatial language production, and later spatial abilities. They found that the spatial language input significantly contributed to spatial language production, impacting later spatial abilities. This result indicated a mediating effect of early spatial language between parental language input and later spatial abilities. Later, Georges et al. (2021) found that both visuospatial and verbal abilities uniquely predicted verbal number skills after controlling age, gender, and socioeconomic status. But the predictive effects of visuospatial and verbal abilities were completely mediated by spatial language. Thus, promoting spatial language in preschoolers could be a successful strategy for developing early mathematic skills. Besides, Bower et al. (2020) established a moderated mediation model to demonstrate the moderating effects of gender, socioeconomic status (SES) on the possible mediation of spatial language on the relationship between spatial skill and mathematics performance. In particular, spatial language mediated the association between spatial skill and mathematics performance only for girls.

\section{Parental influences on early spatial language}

\section{The facilitating influences}

First, Kisa et al. (2019) found that parents' use of spatial words could predict young children's early spatial word comprehension. Second, Ferrara et al. (2011) found that both parents and children produced significantly higher proportions of spatial talk in the guided play condition. They suggested that parents could promote early spatial language through guided play and other learning activities. Finally, Thomson et al. 
(2020) analyzed fathers' spatial support by examining paternal spatial language support's quality and quantity. They found that fathers had more spatial concept support to girls, predicting their higher math scores in Grade 1.

\section{The mediating influences}

Pruden and Levine (2017) found that the later gender difference in the early spatial talk was fully mediated by parental language input when children were 14-26 months old. There was no sex difference in children's spatial-language use. Their finding indicated that parents' earlier spatial-language input mediated the gender differences in early spatial talk.

\section{Research gaps: spatial semantic categories}

Among the 19 studies being reviewed in this study, 17 explored the static category of spatial information, such as locations and relations, while only two have focused on comparing motion events communicated in English and Greek (Johanson et al. 2019; Papafragou and Selimis 2010). Furthermore, all the 19 studies focused only on the non-angular perspectives of spatial information; none mentioned the Frames of Reference in encoding spatial information. Studying spatial semantic categories would provide empirical evidence to understand the relationship between language and thought (event categorization). A review of the existing studies on spatial semantic categories indicated a lack of research on the dynamic category of spatial information (i.e., motion events) and a neglection of Frames of Reference. Motion events expression is a typical way to encode dynamic information in space ( $\mathrm{Ji}$ et al. 2011; Ji and Hohenstein 2017; Papafragou and Selimis 2010), while Frames of Reference serve to encode static information in space (Levinson 2003; Li and Zhang 2009; Levinson and Wilkins 2006; Shusterman and Li 2016), both of which varied across languages depending on different linguistic devices. In this sense, observing how Chinese preschoolers acquire the skills of expressing motion events and their capacity in using the FoRs in the early years might have implications for early language education and cognitive development, thus deserving empirical studies.

\section{Research gaps: methodological matters}

\section{The research languages}

Among the 19 studies reviewed in this article, 15 focused on the English spatial language. Only three were about Greek, one was about Chinese, one was about Italian, one was about Luxembourgish, and one was about Turkish. In particular, the studies on the English language have covered age and gender differences in spatial language skills and relations with math skills (Gilligan-Lee et al. 20 21; Bower et al. 2020; Johanson and Papafragou, 2014; Ralph et al. 2020; Pruden and Levine 2017), the role of language in spatial development (Casasola et al. 2020; Miller et al. 2020; Cohen and Emmons 2017; Verdine et al. 2019), mathematical language (Johnston 
and Degotardi 2020), parental involvement and support (Ferrara et al. 2011; Pruden et al. 2011; Thomson et al. 2020), and motion events (Johanson et al. 2019; Papafragou and Selimis 2010). The Chinese language study examined the Space-Time Metaphor Hypothesis in Early Child Mandarin (Tsung and $\mathrm{Wu} 2021$ ). The Luxembourgish language study examined the role of spatial language between visuospatial abilities and verbal number skills (Georges et al. 2021). The Turkish study (Kisa et al. 2019) explored the relationship between parental spatial language input and children's spatial language development. The Italian study explored the role of spatial locative comprehension in learning and retrieving pathways (Piccardi et al. 2015). It seems that English is the only dominating language in this field of studies. Chinese and other languages, however, have been neglected.

\section{The research approaches}

There is a dichotomy of research design in child language studies: the naturalistic versus experimental approaches. The naturalistic approach employs children's spontaneous/naturalistic production, parental report or diary, and has been widely used in the earliest years of child language study. Its most representative paradigm is the corpus approach, a rapidly growing methodology that uses the statistical analysis of large corpora of written or spoken language to investigate linguistic phenomena. For instance, the study on Chinese spatial language 'qian/hou' by Tsung and Wu (2021) adopted the corpus approach. Johnston and Degotardi (2020) adopted the naturalistic observation method to understand early childhood educators' use of mathematic language when interacting with infants during mealtime. Cohen and Emmons (2017), Pruden and Levine (2017), and Thomson et al. (2020) adopted the naturalistic observation approach to understanding young children's spatial language production and its relationship with parental language input and spatial and math skills. In summary, only six of the 19 chosen studies adopted this naturalistic approach. In contrast, 13 of the 19 reviewed studies adopted the experimental approach, indicating an unbalance between the experimental approach and naturalistic observation in this field.

\section{Discussion}

This scoping review has provided important insights into the studies about the developmental patterns, the roles of early spatial language, parental influences, and research gaps. This section will discuss the major findings and their implications for future studies.

\section{Developmental patterns of early spatial language}

First, this scoping review has identified two studies on the age differences in early spatial language. Their findings jointly indicated that there might be significant age differences in early spatial language, including comprehension and production. However, it 
is important to note that both studies (Gilligan-Lee et al. 2021; Tsung and Wu 2021) adopted a cross-sectional design, which can generate some hints rather than sound evidence to the developmental patterns of early spatial language. Rigorously speaking, the longitudinal design will be more reliable and appropriate to demonstrate the age differences. Also, Gilligan-Lee et al. (2021) simply explored the age difference in English spatial language performance from 6 to 10 years. Only Tsung and Wu (2021) focused on the preschool years and Chinese preschoolers. Further studies with a large-scale sample and longitudinal design are needed to explore early spatial language's developmental patterns.

Second, this scoping review has identified three studies on the gender difference in early spatial language. The findings, however, are contradictory thus have made the gender effect inconclusive so far. For example, Ralph et al. (2020) found that boys outperformed girls by age five because their mothers had more spatial language input for boys in PreK years whereas more for girls in the post-K years. In contrast, Bower et al. (2020) found that the girls had a higher spatial language comprehension than boys around age 3. In addition, Pruden and Levine (2017) found that parents' earlier spatiallanguage input fully mediated this gender difference. Accordingly, the results about gender differences are mixed; thus, desire further studies to explore the gender effect.

\section{The role of early spatial language}

First, this scoping review has identified three studies (Casasola et al. 2020; Miller et al. 2020; Piccardi et al. 2015) on the facilitating role of early spatial language. They conducted some experiments to confirm that spatial language itself or the training could either predict or facilitate early spatial development. However, these studies have adopted a cross-sectional design thus cannot consolidate the cause-effective relationship between early spatial language and later spatial development.

Similarly, the three studies (Bower et al. 2020; Georges et al. 2021; Pruden et al. 2011) on the mediating role of early spatial language have also adopted cross-sectional design to conduct experiments. Their modeling findings are statistically significant; however, the results are not so rigorous. To consolidate their findings, they need to adopt a longitudinal design that could examine the cause-effective relationships. In addition, the three studies have confirmed different models to demonstrate the roles of early spatial language. For example, Pruden et al. (2011) indicated a mediating effect of early spatial language between parental language input and later spatial abilities. But Bower et al. (2020) established a moderated mediation model, demonstrating that gender and socioeconomic status (SES) might moderate spatial language mediation on the relationship between spatial skill and mathematics performance. Future studies should adopt a large-scale sample and longitudinal design to confirm the different early spatial language roles in early childhood development.

\section{Parental involvement and support}

First, this study has identified three studies (Ferrara et al. 2011; Kisa et al. 2019; Thomson et al. 2020) on the facilitating role of parental involvement and support. 
Parental spatial language input is closely linked to children's spatial language development. However, little is known about the quantity and quality of early spatial input and how it could facilitate infants' individual development. Kisa et al. (2019) have filled this research gap by analyzing the spatial input in Turkish-learning infants (ages 16-21 months) in the context of a spatial activity (puzzle play). They found that parental language input could change depending on children's age and spatial vocabulary comprehension and predict their later spatial development. However, in all these three studies, the play settings varied within the sample, which might be a key confounding factor that should have been seriously considered. For example, the parent-child dyads who had more engagement or interest in constructive play (i.e., puzzles, block building, etc.) were more likely to have more parental spatial language input, leading to better spatial ability performance. Therefore, it is still unknown whether the play activities or the language input contributed to the spatial ability. Future studies could consider a set context with a large-scale sample to rule out this confounding factor resulted from the varied activities.

Second, this study has identified one study (Pruden and Levine 2017) on the mediating role of parental language input. The existing studies found that boys produced more spatial terms than girls in the early years, but the parent language input might cause this gender difference. To address this question, Pruden and Levine (2017) followed a diverse sample of 58 parent-child dyads longitudinally to track the development of spatial-language production in young children (ages of 14 and 46 months). They found that the boys produced and heard more spatial words than girls. And the modeling results indicated that the later gender difference in the early spatial talk was fully mediated by parental language input when children were 14-26 months old. There was no sex difference in children's spatial-language use. This longitudinal study has provided sound evidence to confirm that parents' earlier spatial-language input mediated the gender differences in early spatial talk. In contrast, Thomson et al. (2020) could only provide correlational results that cannot confirm the cause-effective relationship. In sum, all these studies have emphasized parental spatial language input, which was based on the hypothesis 'spatial language input contributes to spatial language output'. However, parental involvement in spatial activities or other parent-child interaction types were neglected. It should be noted that the contributors of early spatial language were not limited to 'parental spatial language input'; what parents did in their parenting practices and the home language learning environment they established were also taking a great part in the early development of spatial language.

\section{Research gaps: understudied 'motion events' and 'frames of reference'}

This study has reviewed 19 sources on spatial language in early years, revealing that motion events (as a typical expression of dynamic spatial category) were rarely explored. It is well known that languages differ in how they encode motion. Languages such as English use verbs that communicate the manner of motion (e.g., slide, skip), while languages such as Greek regularly encode motion paths in verbs (e.g., enter, ascend). Studying motion events would provide empirical evidence to 
understand the relationship between language and thought (event categorization). This study has identified only two studies on this topic. Papafragou and Selimis (2010) have explored how crosslinguistic encoding patterns interacted with event cognition by comparing labeling and categorization preferences for motion events in English- and Greek-speaking adults and 5-year-olds. In addition, comparing Greek and English, Johanson et al. (2019) have found that the linguistic asymmetry between the sources and goals of motion events was strong cross-linguistically and could be considered a shared, potentially universal feature of spatial language. These findings have indicated a linguistic asymmetry between the sources and goals of motion events, with goals mentioned more frequently than sources in motion descriptions by both children and adults. The existing studies have compared motion events communicated in English and Greek (Johanson et al. 2019; Papafragou and Selimis 2010). However, Chinese and English do have some striking typological differences in the linguistic representation of space, ranging from the frame of references to the expressions of motion events. The findings from English studies could not directly apply to Chinese young children. Therefore, there is a critical need to explore the Chinese spatial language to understand when and how it is acquired and developed. This exploration will provide linguistically appropriate evidence for understanding early language development and education in Chinese societies.

Besides, this scoping review study collated these 19 sources into angular or non-angular to see if the existing studies adopted a balanced perspective to examine spatial language development. The results indicated that all these sources did not explore the early development and expressions of frames of reference. Different language speakers worldwide might have different preferences in using FoRs, thus providing a suitable scene for analyzing crosslinguistic differences (Levinson 2003). In addition, FoRs serve as a framework to reflect their sense of the relationship between themselves and their surrounding space (Adamou and Shen 2017; Burigo and Schultheis 2018; Levinson 2003). Moreover, children's use of FoRs in their talk also related to their perspective-taking capacity, which develops rapidly during the preschool stage, thus deserves a thorough exploration (Hughes and Donaldson 1979; Inagaki et al. 2002; Newcombe and Huttenlocher 1992; Piaget 2003; Piaget and Inhelder 1956). Thereby, observing how children used FoRs to communicate effectively about their locations and directions is vital to studying spatial language development. However, most of the research on FoRs in the early years focused on non-linguistic tasks, few of them concerned about the related expressions, and none paid attention to the corresponding expressions among children (for non-linguistic experiments in young age, see Adamou and Shen 2017; LeGuen 2011; Li and Zhang 2009; Shinohara and Matsunaka 2004). Future studies are needed to fill this gap.

\section{Research gaps: unbalanced research methods}

First, this literature review found that English is the only dominating language in this field of studies. Scholars have neglected Chinese and other languages. Chinese has a different spatial language system thus deserves a set of empirical studies on acquisition in the early years. 
Second, the naturalistic approach employs children's spontaneous or naturalistic production, parental report or diary, and has been widely used in the earliest years of child language study. Its most representative paradigm is the corpus approach, a rapidly growing methodology that uses the statistical analysis of large corpora of written or spoken language to investigate linguistic phenomena. However, only six of the 19 chosen studies adopted this naturalistic approach. Thus, the experimental approach might be the mainstream in early spatial language research, and the naturalistic observation studies should be strengthened. Nevertheless, the experimental approach is a typical method for studying children's language development in the past decades. It normally employs elicited production, repetition/elicited imitation, syntactic priming, weird word order), comprehension methods (act-out, pointing, intermodal preferential looking, looking while listening, conditioned head-turn preference procedure, functional neuroimaging), and judgment methods (grammaticality/acceptability judgments, yes-no/truth-value judgments) to understand young children's language development (Ambridge and Rowland 2013). However, there are at least 12 obstacles for implementing the experimental design appropriately: (1) choosing an age-appropriate task that makes communicative sense; (2) motivating children to co-operate; (3) choosing a between-/within-subjects design; (4) the use of novel items (e.g., novel verbs); (5) fillers; (6) blocked, counter-balanced and random presentation; (7) the appropriate number of trials and participants; (8) drop-out rates; (9) the importance of control conditions; (10) choosing a sensitive dependent measure; (11) classification of responses; and (12) using an appropriate statistical test (Ambridge and Rowland 2013). Therefore, both naturalistic and experimental approaches should be adopted in early childhood language studies.

\section{Conclusions, limitations, and implications}

This study is the first scoping review to thoroughly examine the existing studies on early spatial language development and education. Using the three common databases (ProQuest, Scopus, and Google Scholar), this study has provided evidencebased answers to the four research questions: the age and gender differences in early spatial language, the role of early spatial language, the influential factors of early spatial language, and research gaps. First, significant age differences were found in most relevant studies, indicating that future studies on Chinese spatial language should examine age differences. Second, conflicting gender differences were found in a few studies, indicating that future Chinese studies should explore any possible gender differences. Third, most relevant studies found that early spatial language could facilitate or predict spatial skills and/or spatial cognition. This finding implies that future Chinese studies should also examine the role of early spatial language. Next, some studies have found that parental language input and parental involvement could enhance early spatial language, indicating the same research direction for future Chinese studies. Last, this study has identified the research gaps in this field: no Chinese studies, very few naturalistic studies, the understudied motion events, and no studies on frames of reference. Therefore, future Chinese studies should focus on the developmental pattern and associated early spatial language predictors 
in Chinese. Special attention should also be paid to spatial language development regarding 'motion events' and 'frames of reference' in Chinese.

Nevertheless, this study has two major limitations. First, it has only searched the three common full-text databases that are comprehensive and inclusive: ProQuest, Scopus, and Google Scholar. Thus, there might be some relevant studies that have not been included in this scoping review. In the future, the other databases, such as EBSCO, JSTOR, Web of Science, and ERIC, should also be included. Second, this scoping review has focused on the 19 English articles identified from international peer-reviewed journals. Those journals in Chinese or other languages could not meet the selection criteria \#1, \#4, \#5, and \#6; thus, they were not included in this scoping review. In the future, to address other research questions, we should set a lenient set of selection criteria to conduct a special review to include some important and highly relevant Chinese articles.

Author contributions DW analyzed the data and wrote the manuscript; HL provided the data, conceptualized the research, and revised the manuscript; SD reviewed and refined the manuscript.

Funding Open Access funding enabled and organized by CAUL and its Member Institutions. This work is financially supported by the iMQRES scholarship provided by Macquarie University.

Data availability The Early Childhood Mandarin Corpus (Li and Tse 2011) is open to psycholinguists for secondary research.

\section{Declarations}

Conflict of interest The authors declare that there are no conflict of interest regarding the publication of this paper.

Ethical approval Secondary data were used in a corpus study.

Animal and human participants This is a scoping review of published journal articles. It has not involved any animals, or human participants thus does not need any ethical clearance.

Open Access This article is licensed under a Creative Commons Attribution 4.0 International License, which permits use, sharing, adaptation, distribution and reproduction in any medium or format, as long as you give appropriate credit to the original author(s) and the source, provide a link to the Creative Commons licence, and indicate if changes were made. The images or other third party material in this article are included in the article's Creative Commons licence, unless indicated otherwise in a credit line to the material. If material is not included in the article's Creative Commons licence and your intended use is not permitted by statutory regulation or exceeds the permitted use, you will need to obtain permission directly from the copyright holder. To view a copy of this licence, visit http://creativecommons.org/licen ses/by/4.0/.

\section{References}

Adamou E, Shen XR (2017) Beyond language shift: spatial cognition among the Ixcatecs in Mexico. J Cogn Cult 17(1-2):94-115

Ambridge B, Rowland CF (2013) Experimental methods in studying child language acquisition. Wiley Interdiscip Rev 4(2):149-168 
Arksey H, O’Malley L (2005) Scoping studies: towards a methodological framework. Int J Soc Res Methodol 8(1):19-32

Balcomb F, Newcombe NS, Ferrara K (2011) Finding where and saying where: developmental relationships between place learning and language in the first year. J Cogn Dev 12(3):315-331

Bohnemeyer J (2020) Linguistic relativity: from whorf to now. In: Gutzmann D, Matthewson L, Meier C, Rullmann H, Zimmermann T (eds) The Wiley Blackwell companion to semantics. Wiley, Hoboken, pp 1-33

Bower CA, Foster L, Zimmermann L, Verdine BN, Marzouk M, Islam S et al (2020) Three-year-olds' spatial language comprehension and links with mathematics and spatial performance. Dev Psychol 56(10): 1894

Bowerman M (1996) Learning how to structure space for language: a crosslinguistic perspective. In: Bloom P, Peterson M, Nadel L, Garrett M (eds) Language and space. MIT Press, Cambridge, MA, pp 385-436

Bowerman M, Choi S (2003) Space under construction: language-specific spatial categorization in first language acquisition. In: Gentner D, Goldin-Meadow S (eds) Language in mind: advances in the study of language and thought. MIT Press, Cambridge, pp 387-427

Burigo M, Schultheis H (2018) The effects of direction and orientation of located objects on spatial language comprehension. Lang Cogn 10(2):298-328

Cannon J, Levine S, Huttenlocher J (2007) A system for analyzing children and caregivers' language about space in structured and unstructured contexts. Spatial Intelligence and Learning Center (SILC) technical report

Casasola M, Cohen LB, Chiarello E (2003) Six-month-old infants' categorization of containment spatial relations. Child Dev 74(3):679-693

Casasola M, Wei WS, Suh DD, Donskoy P, Ransom A (2020) Children's exposure to spatial language promotes their spatial thinking. J Exp Psychol 149:1116

Clements DH, Sarama J, DiBiase AM (eds) (2003) Engaging young children in mathematics: standards for early childhood mathematics education. Routledge

Cohen LE, Emmons J (2017) Block play: spatial language with preschool and school-aged children. Early Child Dev Care 187(5-6):967-977

Ferrara K, Hirsh-Pasek K, Newcombe NS, Golinkoff RM, Lam WS (2011) Block talk: spatial language during block play. Mind Brain Educ 5(3):143-151

Foster EK, Hund AM (2012) The impact of scaffolding and overhearing on young children's use of the spatial terms between and middle. J Child Lang 39(2):338

Gentner D, Bowerman M (2009) Why some spatial semantic categories are harder to learn than others: the typological prevalence hypothesis. In: Crosslinguistic approaches to the psychology of language: research in the tradition of Dan Isaac Slobin, pp 465-480

Gentner D, Özyürek A, Gürcanli Ö, Goldin-Meadow S (2013) Spatial language facilitates spatial cognition: evidence from children who lack language input. Cognition 127(3):318-330

Georges C, Cornu V, Schiltz C (2021) The importance of visuospatial abilities for verbal number skills in preschool: adding spatial language to the equation. J Exp Child Psychol 201:104971

Gilligan-Lee KA, Hodgkiss A, Thomas MS, Patel PK, Farran EK (2021) Aged-based differences in spatial language skills from 6 to 10 years: relations with spatial and mathematics skills. Learn Instr 73:101417

Hermer-Vasquez L, Moffet A, Munkholm P (2001) Language, space, and the development of cognitive flexibility in humans: the case of two spatial memory tasks. Cognition 79(2001):263-281

Hughes M, Donaldson M (1979) The use of hiding games for studying the coordination of viewpoints. Educ Rev 31(2):133-140

Hussein BAS (2012) The Sapir-Whorf hypothesis today. Theory Pract Lang Stud 2(3):642-646

Inagaki H, Meguro K, Shimada M, Ishizaki J, Okuzumi H, Yamadori A (2002) Discrepancy between mental rotation and perspective-taking abilities in normal aging assessed by Piaget's three-mountain task. J Clin Exp Neuropsychol 24(1):18-25

Ji Y, Hendriks H, Hickmann M (2011) How children express caused motion events in Chinese and English: universal and language-specific influences. Lingua 121(12):1796-1819. https://doi.org/10. 1016/j.lingua.2011.07.001

Johanson M, Papafragou A (2014) What does children's spatial language reveal about spatial concepts? Evidence from the use of containment expressions. Cogn Sci 38(5):881-910

Johanson M, Selimis S, Papafragou A (2019) The source-goal asymmetry in spatial language: languagegeneral vs. language-specific aspects. Lang Cogn Neurosci 34(7):826-840 
Johnston K, Degotardi S (2020) 'More than 'more': quantity and quality of mathematical language used by educators in mealtimes with infants. Int J Early Years Educ. https://doi.org/10.1080/09669760. 2020.18485

Kısa YD, Aktan-Erciyes A, Turan E, Göksun T (2019) Parental use of spatial language and gestures in early childhood. Br J Dev Psychol 37(2):149-167

Landau B, Jackendoff R (1993) "What" and "where" in spatial language and spatial cognition. Behav Brain Sci 16:217-217

Lawton CA (1994) Gender differences in way-finding strategies: relationship to spatial ability and spatial anxiety. Sex Roles 30(11):765-779

LeGuen O (2011) Speech and gesture in spatial language and cognition among the Yucatec Mayas. Cogn Sci 35(5):905-938

Levac D, Colquhoun H, O’Brien KK (2010) Scoping studies: advancing the methodology. Implement Sci $5(1): 69$

Levine SC, Vasilyeva M, Lourenco SF, Newcombe NS, Huttenlocher J (2005) Socioeconomic status modifies the sex difference in spatial skill. Psychol Sci 16(11):841-845

Levine SC, Ratliff KR, Huttenlocher J, Cannon J (2012) Early puzzle play: a predictor of preschoolers' spatial transformation skill. Dev Psychol 48(2):530

Levinson SC (2003) Space in language and cognition: explorations in cognitive diversity, vol 5. Cambridge University Press, Cambridge

Levinson SC, Wilkins DP (eds) (2006) Grammars of space: explorations in cognitive diversity. Cambridge University Press, Cambridge. https://doi.org/10.1017/CBO9780511486753

Li H, Tse SK (2011) The early child Mandarin corpus. The University of Hong Kong, Hong Kong

Li J, Zhang K (2009) Regional differences in spatial frame of reference systems for people in different areas of China. Percept Mot Skills 108(2):587-596

Lightfoot D (2010) Language acquisition and language change. Wiley Interdisciplinary Reviews: CognitiveScience 1(5):677-684

Meints K, Plunkett K, Harris PL, Dimmock D (2002) What is 'on' and 'under' for 15-, 18-and 24-month-olds? Typicality effects in early comprehension of spatial prepositions. Br J Dev Psychol 20(1):113-130

Miller HE, Patterson R, Simmering VR (2016) Language supports young children's use of spatial relations to remember locations. Cognition 150:170-180

Miller HE, Andrews CA, Simmering VR (2020) Speech and gesture production provide unique insights into young children's spatial reasoning. Child Dev 91(6):1934-1952

Munnich E, Landau B, Dosher BA (2001) Spatial language and spatial representation: a crosslinguistic comparison. Cognition 81(3):171-208

Newcombe N, Huttenlocher J (1992) Children's early ability to solve perspective-taking problems. Dev Psychol 28(4):635

Pang LJ, Li H (1993) Infant psychology, Chinese. Zhejiang Education Publishing House, Hangzhou

Papafragou A, Selimis S (2010) Event categorisation and language: a crosslinguistic study of motion. Lang Cogn Process 25(2):224-260

Piaget J (1926) The language and thought of the child. Routledge \& Kegan Paul, London

Piaget J (1928) The child's conception of the world. Routledge and Kegan Paul, London

Piaget J (2003) The psychology of intelligence. Routledge, London

Piaget J, Inhelder B (1956) The child's conception of space. Routledge and Kegan Paul, New York

Piccardi L, Palermo L, Bocchi A, Guariglia C, D'Amico S (2015) Does spatial locative comprehension predict landmark-based navigation? PLoS ONE 10(1):e0115432

Polinsky N, Perez J, Grehl M, McCrink K (2017) Encouraging spatial talk: using children's museums to bolster spatial reasoning. Mind Brain Educ 11(3):144-152

Pruden SM, Levine SC (2017) Parents' spatial language mediates a sex difference in preschoolers' spatial-language use. Psychol Sci 28(11):1583-1596

Pruden SM, Levine SC, Huttenlocher J (2011) Children's spatial thinking: does talk about the spatial world matter? Dev Sci 14(6):1417-1430

Quinn PC, Adams A, Kennedy E, Shettler L, Wasnik A (2003) Development of an abstract category representation for the spatial relation between in 6-to 10-month-old infants. Dev Psychol 39(1):151

Ralph YK, Berinhout K, Maguire MJ (2020) Gender differences in mothers' spatial language use and children's mental rotation abilities in Preschool and Kindergarten. Dev Sci 24:e13037

Shinohara K, Matsunaka Y (2004) Spatial cognition and linguistic expression: empirical research on frames of reference in Japanese. Annu Rev Cogn Ling 2(1):261-283 
Shusterman A, Li P (2016) Frames of reference in spatial language acquisition. Cogn Psychol 88:115-161

Spelke ES (2000) Core knowledge. Am Psychol 55(11):1233

Spelke ES (2011) Natural number and natural geometry. In: Space, time and number in the brain. Academic Press, pp 287-317

Szechter LE, Liben LS (2004) Parental guidance in preschoolers' understanding of spatial-graphic representations. Child Dev 75(3):869-885

Thomson D, Casey BM, Lombardi CM, Nguyen HN (2020) Quality of fathers' spatial concept support during block building predicts their daughters' early math skills-but not their sons'. Early Child Res Q 50:51-64

Tsung L, Wu D (2021) A corpus-based comparison of the pragmatic use of qian and hou to examine the applicability of space-time metaphor hypothesis in early child mandarin. Front Psychol 11:3765

Tzuriel D, Egozi G (2010) Gender differences in the spatial ability of young children: the effects of training and processing strategies. Child Dev 81(5):1417-1430

Verdine BN, Golinkoff RM, Hirsh-Pasek K, Newcombe NS, Filipowicz AT, Chang A (2014) Deconstructing building blocks: preschoolers' spatial assembly performance relates to early mathematical skills. Child Dev 85(3):1062-1076

Verdine BN, Zimmermann L, Foster L, Marzouk MA, Golinkoff RM, Hirsh-Pasek K, Newcombe N (2019) Effects of geometric toy design on parent-child interactions and spatial language. Early Child Res Q 46:126-141

Wallentin M, Østergaard S, Lund TE, Østergaard L, Roepstorff A (2005) Concrete spatial language: see what I mean? Brain Lang 92(3):221-233

Weist RM, Lymburner NL, Piotrowski S, Stoddard JL (2000) Spatial complexity in children's language. Percept Mot Skills 91(2):425-434

Wu D, Lau C, Li H (2018) "Physical Space First!": a corpus-based study on the use of localizer 'shang' in early child mandarin. Corpus Pragmat 2(2):149-166 